Practice Current: An interactive exchange on controversial topics Luca Bartolini, MD, Section Editor

\title{
When do you stop antiepileptic drugs in patients with genetic generalized epilepsies and in those with focal epilepsies?
}

Luca Bartolini, MD

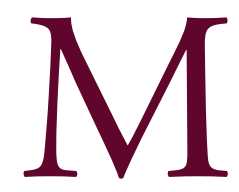

ore than 50 million people worldwide have epilepsy. ${ }^{1}$ About two-thirds of them are well-controlled on 1 or 2 appropriately used antiepileptic drugs (AEDs). ${ }^{2}$ One-third of patients with epilepsy remain refractory to medications, and experience seizures despite a complex regimen of multiple drugs. Some patients may be candidates for surgical interventions, either curative or palliative. Many times in clinical practice the question arises as to whether a patient is a candidate for withdrawing AEDs, either because the epilepsy is well-controlled medically or because the patient became seizure-free after surgery.

Withdrawing AEDs in a patient with chronic epilepsy has many implications. The main risk is that of seizure relapse, as highlighted by several studies ${ }^{3}$; other than the potential harm related to the seizure itself,

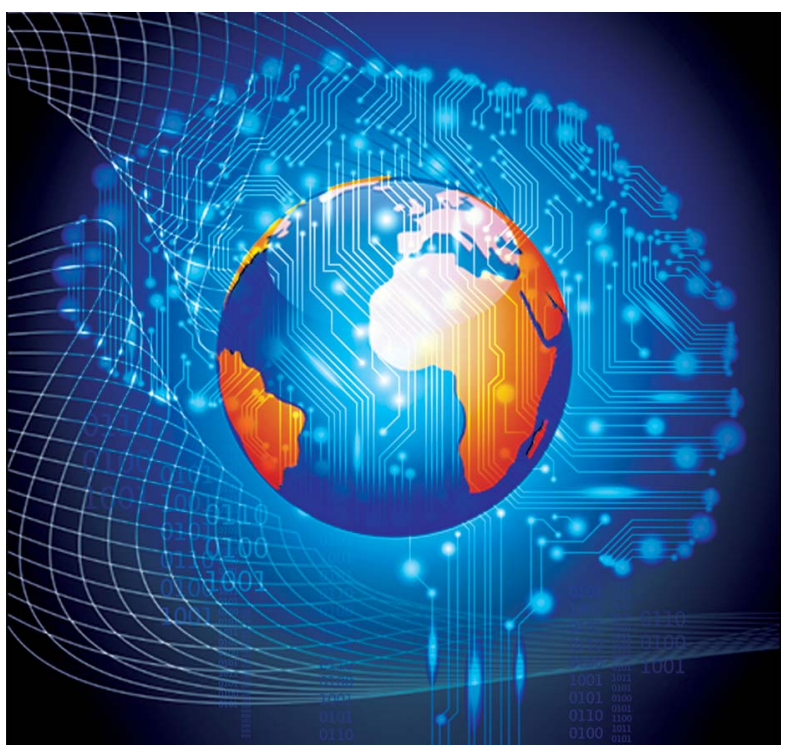
there also exists a small but not negligible possibility of developing refractory seizures. ${ }^{4}$ Specific risk factors for seizure recurrence during AED withdrawal have been identified (table). Moreover, a patient's ability to drive, operate equipment or power tools, or engage in certain daily life activities and sports may be hampered by a seizure relapse. It is unclear how much time of seizure freedom before initiating AED withdrawal decreases the chance of recurrence. On the other hand, withdrawing AEDs may have several beneficial implications: a reduction in side effects, ${ }^{5}$ especially for patients on certain older medications, or those on polytherapy; a decrease in financial burden for both the individual and public health systems worldwide ${ }^{1}$; and the advantage of not taking medications for women seeking pregnancy. ${ }^{6}$ Despite a clear effect on society of the decision to withdraw AEDs, the evidence to guide this process is lacking. 
Table Risk factors for seizure recurrence after withdrawal of antiepileptic drugs ${ }^{19,24}$

Prior failed withdrawal

Epileptiform discharges on EEG at time of withdrawal

Worsening EEG after discontinuation

Onset of epilepsy at age $<2$ years or $>10$ years

$\mathrm{IQ}<70$

History of multiple seizures (>5/y) or status epilepticus

Focal epilepsy

Juvenile myoclonic epilepsy

Abnormal neurologic examination

Remote symptomatic etiology

Childhood epileptic encephalopathies

Incomplete resection of epileptogenic zone

Polytherapy

\section{Current evidence}

When do you withdraw AEDs in patients with genetic generalized epilepsies (GGEs) who have experienced a seizure remission? GGE is the current terminology for idiopathic generalized epilepsy. ${ }^{7}$ This broad group comprises several subtypes, some of which have childhood onset and persist into adulthood. Evidence to guide AED withdrawal in this population of patients is lacking, as the majority of available studies on AED discontinuation in patients managed medically include primarily individuals with focal epilepsies (FEs).

Juvenile myoclonic epilepsy (JME), a common form of GGE, accounts for up to $10 \%$ of all cases of epilepsy and is usually diagnosed in adolescence. Clinically, it is characterized by myoclonic seizures, generalized tonic-clonic seizures, and absences, ${ }^{8}$ and seizures are often seen upon awakening. This condition is usually responsive to medications, but is traditionally considered lifelong; many expert commentaries support the concept of long-term treatment in these patients, based on a very high risk of relapse. ${ }^{9}$ In a study of 186 patients, of the $92 \%$ who achieved remission, only 6 remained seizure-free without medication at a median follow-up of 14 years. ${ }^{10}$ Other studies indicate that not all patients with JME experience a seizure recurrence or disabling seizures once off AEDs. A study followed 23 patients with JME for more than 20 years. ${ }^{11}$ At the end of the follow-up, of the $48 \%$ patients $(n=11)$ who were off AEDs, 6 were seizure-free, 3 had only myoclonus, and 2 had rare seizures. A cohort of 31 patients ${ }^{12}$ was followed for at least 25 years and showed that $68 \%$ of patients $(n=21)$ became seizure-free and AEDs were discontinued in $30 \%$ of them $(n=6)$. Patients with photoparoxysmal response on EEG were found to have higher risk of recurrence. Another study on 66 patients ${ }^{13}$ reported seizure freedom in $59 \%$ of patients; $28 \%$ of them $(n=11)$ were off AEDs for more than 5 years at a median follow-up of 45 years.

Overall, the difference in outcome for patients with JME may be explained by the fact that this syndrome is heterogeneous and has considerable overlap with other forms of epilepsy such as generalized tonic-clonic seizures (GTCS) alone and childhood absence epilepsy. ${ }^{14}$

A study ${ }^{15}$ tried to identify risk factors for relapse after AED withdrawal in a cohort of patients with GGE; it included 17 patients with JME, 31 with childhood and juvenile absence epilepsy, and 10 with GTCS alone. GTCS and GTCS combined with myoclonic or absence seizures (hazard ratio [HR] 2.12; 95\% confidence interval [CI] 1.13-4.3) and worsening interictal EEG during or after AED withdrawal (HR 4.00; 95\% CI 1.39-11.5) were associated with increased risk of recurrence. 
When do you stop AEDs in patients with FEs of unknown cause? The majority of focal FEs are due to an underlying structural cause, such as mesial temporal lobe sclerosis or focal cortical dysplasia. Patients with these forms of $\mathrm{FE}$ are often referred to tertiary care centers for surgical evaluation and treatment. Discontinuation of AEDs after epilepsy surgery is the subject of a longstanding debate in the epilepsy community ${ }^{16}$ and is discussed in the experts' interviews linked to this article.

$\mathrm{FE}$ of unknown cause comprises about one-quarter of all FEs. ${ }^{17}$ It is widely accepted in the literature that the presence of focal seizures carries a higher risk of recurrence after AED withdrawal. ${ }^{18}$ Most studies, though, describe a heterogeneous population of patients with localization-related epilepsy and do not exclude patients with a known cause (either structural or genetic) from their analysis.

Two randomized nonblinded studies on children with FE were included in a recent Cochrane review. ${ }^{19}$ A total of 180 patients with focal seizures were randomized in early and late withdrawal groups. The first study had broad inclusion criteria and excluded only children with cerebral palsy, moderate to severe intellectual disability, or specific epileptic encephalopathies. ${ }^{20}$ The second study included only children with unknown cause for the FE and normal EEG at the time of discontinuation of AEDs. ${ }^{21}$ The conclusion was that the pooled risk ratio was 1.51 (95\% CI 0.97-2.35, $p=0.07$ ), favoring late discontinuation (after at least 2 seizure-free years) of AEDs in children with FE.

The first randomized, double-blind, controlled trial of AED withdrawal in adult epilepsy patients who had been seizure-free for at least 2 years was done in Norway and published in $2008 .^{3}$ A total of 160 patients were randomized to AED withdrawal vs continuation. Patients with JME and GTCS alone were excluded from the trial and about three-quarters of patients had FE. About $70 \%$ of patients in each arm had unknown cause for their FE and none of the patients had had epilepsy surgery. Individuals were followed in the double-blinded period for 12 months or until seizure relapse; then, in the open phase, $89 \%$ who were in the AED continuation group were taken off medications and additional data on seizure recurrence were collected for a median of 47 months. The authors found that at the blinded 12-month follow-up, 7\% of patients who were still on medications had a relapse, vs $15 \%$ of those who discontinued the AEDs (relative risk 2.46; 95\% CI 0.85-7.08; $p=0.095$ ). They also observed a declining monthly risk of seizure recurrence in the combined group of patients who in the study or open phase discontinued their AEDs from 0.010 immediately after withdrawal to 0.003 at 36 months (95\% CI 0.000-0.007). They concluded that if recurrence happens after discontinuation, it happens in the first 6-9 months and that at the 24-month follow-up the risk of relapse is similar for patients who withdrew AEDs during the study phase or afterwards during the open phase.

A longitudinal study analyzed 82 patients with childhood-onset cryptogenic FE, who had at least 5 years of follow-up. ${ }^{22}$ AEDs were withdrawn in the majority of patients after at least 3 years of seizure freedom and only if the EEG did not show epileptiform discharges right before withdrawal. The overall relapse rate was low at $9.8 \%$ and did not correlate with the length of the seizure-free period before initiation of AED withdrawal. Multivariate analysis identified 2 risk factors for relapse: the time from the start of treatment to seizure control (HR 3.50; 95\% CI 0.60-20.35) and age at onset of seizures greater than 6 years (HR 19.24; 95\% CI 1.83-202.44).

\section{Expert opinions}

Three experts were asked to comment on the following questions, with no reference to a specific epilepsy type:

Supplemental Data

Neurology.org/cp
1. When do you stop AEDs after epilepsy surgery?

2. When do you stop AEDs in patients managed medically?

Expert opinion highlights (full interview summaries available as supplemental data at Neurology.org/cp): 


\section{In low-income countries, it is very important to withdraw AEDs as soon as possible because of the costs (A. Asadi-Pooya).}

Gregory D. Cascino, MD, FAAN (United States) First we have to decide what the indications for withdrawal of AED therapy are. If the patient has AED-related side effects or is on polypharmacy, we may consider a reduction of AEDs as soon as several weeks after surgery. Before considering withdrawal of AEDs it is usually advisable to wait for at least 1 year, to ensure that the patient is really seizure-free and not just experiencing a reduction in seizure frequency. I typically wait about 2 years or even longer for AED discontinuation unless there is a strong compelling indication for an earlier termination in medical treatment. If patients have a history of multiple seizures, they are probably at higher risk of seizure recurrence compared to the general population for at least 2-5 years.

If we decide to pursue AED withdrawal, I usually taper the medication over several weeks.

I cannot emphasize this enough: my goal is no seizures, no side-effects, and no lifestyle limitations. Whatever accomplishes those 3 goals is the key to successful care.

Ley Sander, MD, PhD, FRCP (United Kingdom) If the patient for example is taking 3 drugs, we might want to discontinue 1 drug starting at 6 months after surgery. After that, maybe we would consider taking off the second drug after a year, and I would leave the patient on monotherapy for at least another year before we discuss what he or she wants to do. In summary, I would wait at least 6 months but most likely a year and I would always take the patient's wishes and willingness to take the risk of recurrence into account. I usually take into consideration the patient's perception of what drug has been less effective to start the process but I also consider in the equation that some older drugs, particularly enzyme inducers, may have worse side effects, and I may decide to taper off these medications first. For example, if a patient is on 1,000 mg of carbamazepine, I might start monthly decrements of $200 \mathrm{mg}$, and of course this will take a few months for the patient to come off the drug.

Ali A. Asadi-Pooya, MD (Iran) In low-income countries, it is very important to withdraw AEDs as soon as possible because of the costs. If a patient has been seizure-free for at least 1 year after surgery, with no clinical evidence of recurrent seizures, we can discuss the concept of AED withdrawal with the patient. It is an individualized decision, but it should be done soon, unless there is a clear reason not to come off medications. In patients on medical therapy, this decision has to be based on the specific epilepsy syndrome that the patient has: for example, if someone has JME, this is likely a lifelong condition and withdrawing AEDs may not be feasible. If you decide to withdraw AEDs, it is not uncommon to do it over the course of 2-4 months. If the patient is on polytherapy, a slow taper of 1 drug every 2-3 months is suggested. Being on multiple drugs is a risk factor for recurrence, so these patients are particularly challenging. I personally wean off one medication, wait a couple of years, then if the patient is seizure-free I try to discontinue all AEDs.

\section{Preliminary survey results (October 7, 2016)}

We collected 309 responses since September 13, 2016, with slightly more than half from the United States $(\mathrm{n}=157)$. Fifty-four percent $(\mathrm{n}=165)$ of survey takers identify themselves as neurophysiologists/epileptologists and the majority of all responders treat adults only $(63 \% ; \mathrm{n}=195)$. There is no consensus as to when to taper AEDs after temporal lobectomy in a seizure- and aura-free patient: $25 \%(\mathrm{n}=77)$ would start 1 year 


\section{Figure Interactive world map}
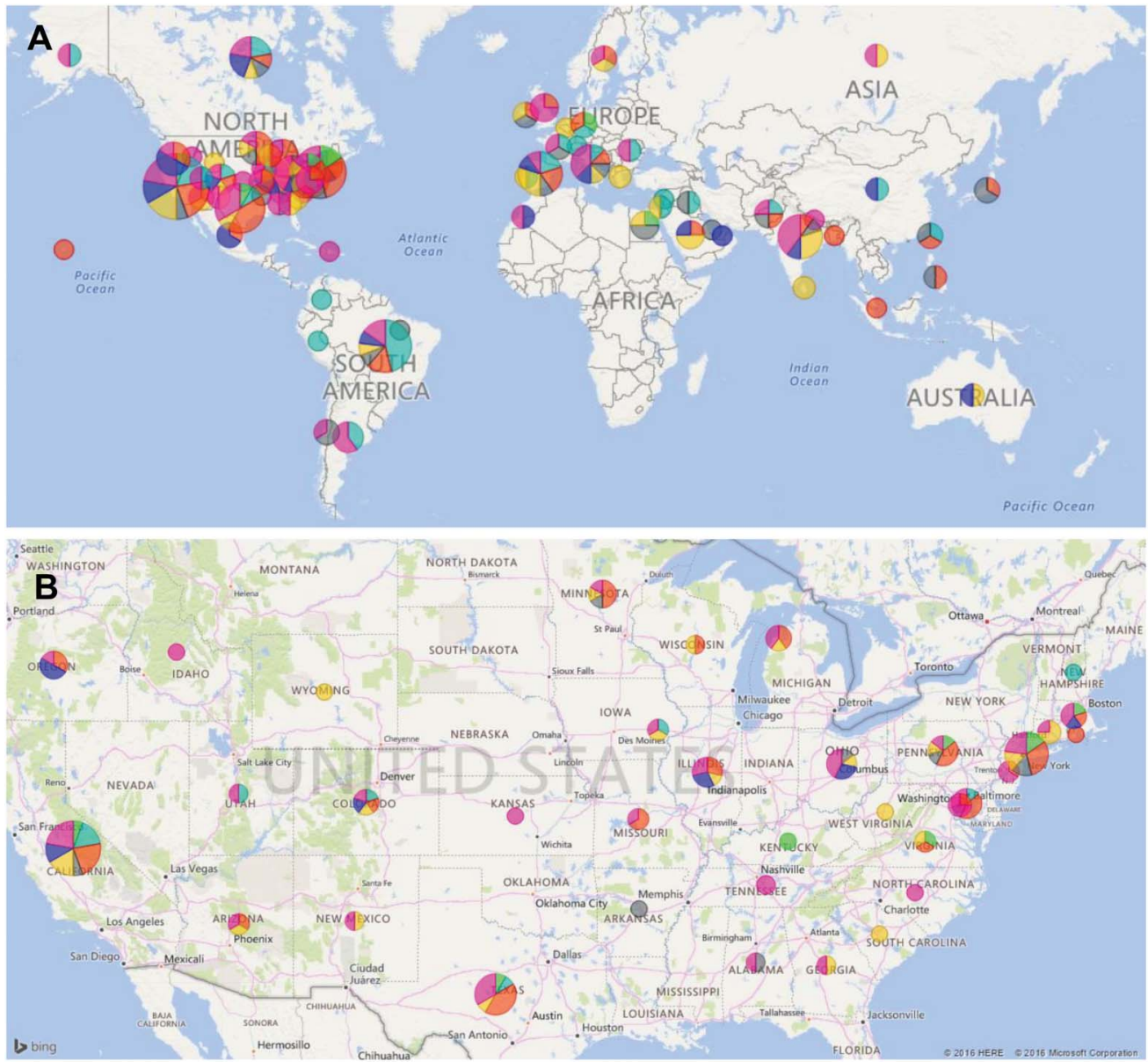

Other

Taper one of the two AEDs now, with the goal of lifelong monotherapy

Taper one of the two AEDs now, with the goal of withdrawing all AEDs

Wait for a total of 2 years then taper one of the two AEDs, with the goal of lifelong monotherapy

Wait for a total of 2 years then taper one of the two AEDs, with the goal of withdrawing all AEDs

Wait for another 6 months then taper one of the two AEDs, with the goal of lifelong monotherapy

Wait for another 6 months then taper one of the two AEDs, with the goal of withdrawing all AEDs

(A) Snapshot of the interactive world map (http://tinyurl.com/NCPCP3) displays results for the question of antiepileptic drug (AED) discontinuation after temporal lobectomy; the size of the pie charts is proportional to the number of responses from each country or state. (B) Zoomed snapshot of the interactive map centered on the United States, displaying lack of consensus across the country about the same question.

after surgery, $21 \%(\mathrm{n}=64)$ would start 6 months after surgery, and $17 \%(\mathrm{n}=54)$ would start after 2 years (figure). The reported goal for $63 \%$ of responders $(n=195)$ is withdrawing all AEDs, as opposed to lifelong monotherapy for $34 \%$.

The majority of responses about AED discontinuation in a patient with FE on unknown etiology and abnormal EEG favor waiting for 2 years of seizure freedom $(47 \% ; n=144)$ and obtaining a repeat EEG and waiting longer if not normalized $(50 \% ; \mathrm{n}=119)$. 
While the majority do not recommend tapering AEDs in patients with JME (57\%; $\mathrm{n}=175)$, it is interesting that $22 \%(\mathrm{n}=67)$ would start the taper after 2 years of seizure freedom.

\section{CONCLUSION}

Discontinuation of AEDs is a controversial topic that has generated much attention in the epilepsy community over the last 20 years. The quality of the available evidence, however, remains low or absent.

There is never going to be a one-size-fits-all solution, considering the number of variables that come into play. In most cases, this remains primarily a decision driven by the underlying pathology and the patient's wishes.

Systematic reviews, meta-analyses, and practice recommendations ${ }^{23}$ have analyzed different epilepsies treated medically and those treated surgically as a whole, but the individual studies often include heterogeneous populations and results may be difficult to interpret. In what specific epilepsies should the 2-year seizure freedom cutoff be used when considering AED withdrawal? Are there certain groups of patients for whom AEDs could be safely discontinued after only 1 year? These controversies highlight the need for studies of AED withdrawal in specific populations, such as patients with $\mathrm{JME}^{11}$ or patients with FE of unknown cause.

\section{Gregory D. Cascino, MD, FAAN, is the Whitney}

MacMillan, Jr. Professor of Neuroscience at the Mayo Clinic College of Medicine. He is also the Enterprise Director of Epilepsy at Mayo Clinic. His interests have included neuroimaging in epilepsy and the identification of surgically remediable epileptic syndromes in patients with drug-resistant focal epilepsy. He has published over 200 peerreviewed articles and presented over 350 invited lectures. Dr. Cascino served as a site principal investigator in the $\mathrm{NIH}$-funded multicenter Epilepsy Phenome Genome Project and the Human Epilepsy Project. He is currently an Associate Editor of Neurology ${ }^{\circledR}$, Chair of the American Academy of Neurology Member Engagement

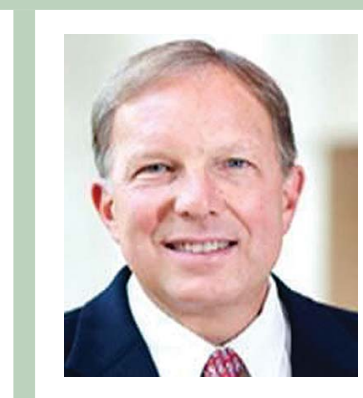

Committee, and a member of the AAN Board of Directors. He was the recipient of the American Epilepsy Society 2013 J. Kiffin Penry Excellence in Epilepsy Care Award.

Ley Sander, MD, PhD, FRCP, is the Epilepsy Society Professor of Neurology at UCL Institute of Neurology and Consultant Neurologist at the National Hospital, Queen Square, London. He is the Medical Director of the Chalfont Centre for Epilepsy and R\&D Director of Stichting Epilepsie Instellingen Nederland. He is the recipient of several awards including the Research Recognition Award for Clinical Sciences of the American Epilepsy Society, BUPA Foundation Epidemiology Award, the Gower's Prize, and the Ambassador for Epilepsy Award. He has more than 600 publications to his name and his main research interests are in the epidemiology and genetics of epilepsy, the management of chronic epilepsy particularly with new antiepileptic drugs, and the delivery of epilepsy care in resource-poor settings. 


\section{Ali A. Asadi-Pooya, MD, is an Associate Professor of Epileptology at the Department of Neurology, Shiraz University of Medical Sciences, Shiraz, Iran. He is the founder and the director of Shiraz Epilepsy Center and the director of Shiraz Epilepsy Surgery Committee. He completed his fellowship in epilepsy and clinical neurophysiology at Thomas Jefferson University, Philadelphia, PA (a 2-year fellowship from 2006 until 2008). He returned to Iran in 2008 and has been working as an epileptologist since September 2008. He is also an adjunct research faculty at the Department of Neurology, Thomas Jefferson University.}

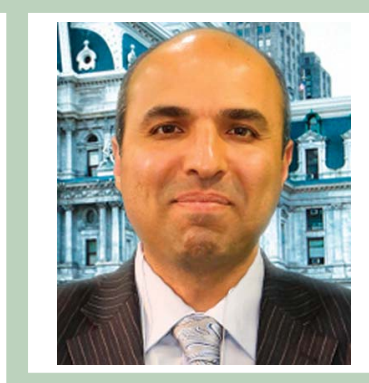

\section{REFERENCES}

1. WHO. Epilepsy fact sheet [online]. 2016. Available at: http://www.who.int/mediacentre/factsheets/ fs999/en/. Accessed June 16, 2016.

2. Kwan P, Brodie MJ. Early identification of refractory epilepsy. N Engl J Med 2000;342:314-319.

3. Lossius MI, Hessen E, Mowinckel P, et al. Consequences of antiepileptic drug withdrawal: a randomized, double-blind study. Epilepsia 2008;3:455-463.

4. Sillanpää M, Schmidt D. Prognosis of seizure recurrence after stopping antiepileptic drugs in seizure-free patients: a long-term population-based study of childhood-onset epilepsy. Epilepsy Behav 2006;8:713-719.

5. Kuzniecky R, Rubin ZK, Faught E, Morawetz R. Antiepileptic drug treatment after temporal lobe epilepsy surgery: a randomized study comparing carbamazepine and polytherapy. Epilepsia 1992;33: 908-912.

6. Sander JW. Stopping antiepileptic drug treatment. In: Lecture notes from the Biannual Epilepsy Teaching Weekend: UK Chapter of the International League Against Epilepsy [online], 15th ed, ch 32. Available at: https://www.epilepsysociety.org.uk/sites/default/files/attachments/Chapter32Sander2015. pdf. Accessed June 17, 2016.

7. Gallentine WB, Mikati MA. Genetic generalized epilepsies. J Clin Neurophysiol 2012;29:408-419.

8. Murthy JM, Rao CM, Meena AK. Clinical observations of juvenile myoclonic epilepsy in 131 patients: a study in South India. Seizure 1998;7:43-47.

9. Camfield P, Camfield C. When is it safe to discontinue AED treatment? Epilepsia 2008;49(suppl 9): 25-28.

10. Chowdhury A, Brodie MJ. Pharmacological outcomes in juvenile myoclonic epilepsy: support for sodium valproate. Epilepsy Res 2016;119:62-66.

11. Camfield CS, Camfield PR. Juvenile myoclonic epilepsy 25 years after seizure onset: a populationbased study. Neurology 2009;73:1041-1045.

12. Geithner J, Schneider F, Wang Z, et al. Predictors for long-term seizure outcome in juvenile myoclonic epilepsy: 25-63 years of follow-up. Epilepsia 2012;53:1379-1386.

13. Senf P, Schmitz B, Holtkamp M, Janz D. Prognosis of juvenile myoclonic epilepsy 45 years after onset: seizure outcome and predictors. Neurology 2013;81:2128-2133.

14. Brodie MJ. Modern management of juvenile myoclonic epilepsy. Expert Rev Neurother 2016;16: 681-688.

15. Pavlović M, Jović N, Pekmezović T. Antiepileptic drugs withdrawal in patients with idiopathic generalized epilepsy. Seizure 2011;20:520-525.

16. Cole AJ, Wiebe S. Debate: should antiepileptic drugs be stopped after successful epilepsy surgery? Epilepsia 2008;49(suppl 9):29-34.

17. Benbadis SR. Localization-related (focal) epilepsy: causes and clinical features [online]. Available at: http://www.uptodate.com/contents/localization-related-focal-epilepsy-causes-and-clinical-features? source $=$ see_link\&sectionName $=$ CLINICAL + FEATURES\&anchor $=$ H7\#H7 Accessed July 29, 2016.

18. Beghi E, Giussani G, Grosso S, et al. Withdrawal of antiepileptic drugs: guidelines of the Italian League Against Epilepsy. Epilepsia 2013;54(suppl 7):2-12.

19. Strozzi I, Nolan SJ, Sperling MR, Wingerchuk DM, Sirven J. Early versus late antiepileptic drug withdrawal for people with epilepsy in remission. Cochrane Database Syst Rev 2015:CD001902.

20. Braathen G, Melander H. Early discontinuation of treatment in children with uncomplicated epilepsy: a prospective study with a model for prediction of outcome. Epilepsia 1997;38:561-569.

21. Verrotti A, Morresi S, Basciani F, Cutarella R, Morgese G, Chiarelli F. Discontinuation of anticonvulsant therapy in children with partial epilepsy. Neurology 2000;55:1393-1395. 
22. Ohta H, Ohtsuka Y, Tsuda T, Oka E. Prognosis after withdrawal of antiepileptic drugs in childhoodonset cryptogenic localization-related epilepsies. Brain Dev 2004;26:19-25.

23. WHO. When to discontinue antiepileptic drug treatment in adults and children: evidence-based recommendations for management of epilepsy and seizures in non-specialized health settings [online]. Available at: http://www.who.int/mental_health/mhgap/evidence/epilepsy/q9/en/. Accessed June 16, 2016.

24. Braun KP, Schmidt D. Stopping antiepileptic drugs in seizure-free patients. Curr Opin Neurol 2014; 27:219-226.

\section{AUTHOR CONTRIBUTIONS}

L. Bartolini designed and drafted the article and interviewed the experts.

\section{STUDY FUNDING}

No targeted funding reported.

\section{DISCLOSURES}

L. Bartolini serves as the Practice Current Section Editor for Neurology ${ }^{\circledR}$ Clinical Practice. Full disclosure form information provided by the author is available with the full text of this article at Neurology.org/cp.

\section{Related articles from AAN physician and patient resources}

\section{Neurology ${ }^{\circledR} \quad$ - Neurology.org}

A targeted resequencing gene panel for focal epilepsy April 26, 2016;86:1605-1612.

\section{Neurology ${ }^{\circledR}$ Genetics • Neurology.org/ng}

Copy number variants in absence epilepsy: Further complications of the picture April 2016;2:e67.

\section{Continuum ${ }^{\circledR}$ - ContinuumJournal.com}

Imaging for Adults With Seizures and Epilepsy

October 2016;22:1451-1479.

Diagnosis of Epilepsy and Related Episodic Disorders

February 2016;22:15-37.

Management of Drug-Resistant Epilepsy

February 2016;22:157-172.

\section{Neurology Today ${ }^{\circledR} \quad$ - Neurotodayonline.com}

NEWS FROM THE AMERICAN EPILEPSY SOCIETY ANNUAL MEETING: One in Ten Drug-Resistant Juvenile Myoclonic Epilepsy Patients Share Common Copy Number Variants January 7, 2016;16:7-8.

Is Screening for Genotypes Linked to Epilepsy Medication-Related Complications

Cost-Effective?

March 17, 2016;16:1,26-27. 


\section{Neurology ${ }^{\circ}$ Clinical Practice}

Practice Current: When do you stop antiepileptic drugs in patients with genetic generalized epilepsies and in those with focal epilepsies?

Luca Bartolini

Neurol Clin Pract 2016;6;530-537 Published Online before print November 23, 2016

DOI 10.1212/CPJ.0000000000000326

This information is current as of November 23, 2016

Neurol Clin Pract is an official journal of the American Academy of Neurology. Published continuously since 2011, it is now a bimonthly with 6 issues per year. Copyright ( 2016 American Academy of Neurology. All rights reserved. Print ISSN: 2163-0402. Online ISSN: 2163-0933.

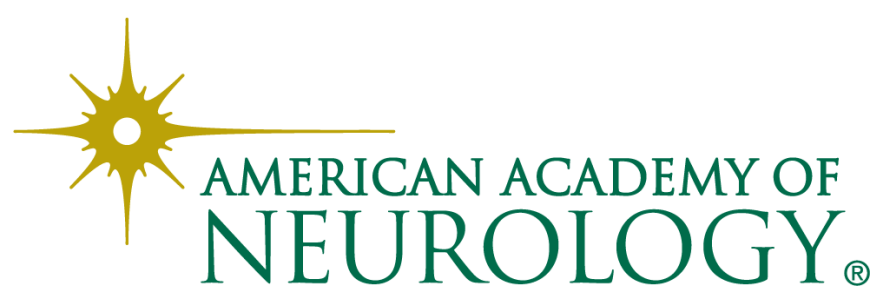




\section{Updated Information \& Services}

\section{Supplementary Material}

\section{References}

Citations

Subspecialty Collections

Permissions \& Licensing

\section{Reprints}

including high resolution figures, can be found at: http://cp.neurology.org/content/6/6/530.full.html

Supplementary material can be found at: http://cp.neurology.org/content/suppl/2016/11/23/CPJ.0000000000000 326.DC1

http://cp.neurology.org/content/suppl/2016/11/23/CPJ.0000000000000 326.DC2

This article cites 19 articles, 0 of which you can access for free at: http://cp.neurology.org/content/6/6/530.full.html\#\#ref-list-1

This article has been cited by 1 HighWire-hosted articles: http://cp.neurology.org/content/6/6/530.full.html\#\#otherarticles

This article, along with others on similar topics, appears in the following collection(s):

All Epilepsy/Seizures

http://cp.neurology.org//cgi/collection/all_epilepsy_seizures

Antiepileptic drugs

http://cp.neurology.org//cgi/collection/antiepileptic_drugs

Generalized seizures

http://cp.neurology.org//cgi/collection/generalized_seizures

Partial seizures

http://cp.neurology.org//cgi/collection/partial_seizures

Practice Current

http://cp.neurology.org//cgi/collection/practice_current

Information about reproducing this article in parts (figures,tables) or in its entirety can be found online at:

http://cp.neurology.org/misc/about.xhtml\#permissions

Information about ordering reprints can be found online:

http://cp.neurology.org/misc/addir.xhtml\#reprintsus

Neurol Clin Pract is an official journal of the American Academy of Neurology. Published continuously since 2011, it is now a bimonthly with 6 issues per year. Copyright $\odot 2016$ American Academy of Neurology. All rights reserved. Print ISSN: 2163-0402. Online ISSN: 2163-0933.

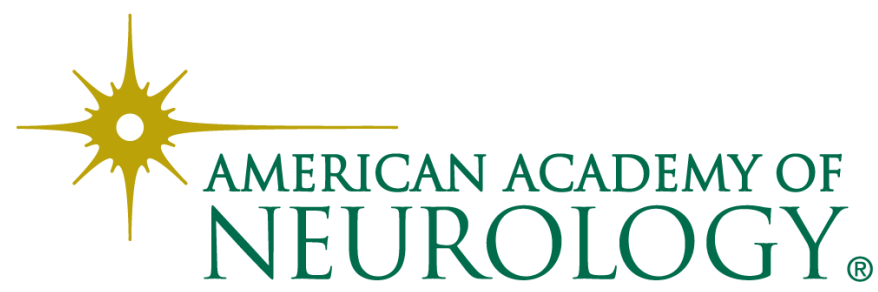

